\title{
RESPONSE SURFACE METHODOLOGY APPLIED TO OXALIC ACID HYDROLYSIS OF OIL PALM EMPTY FRUIT BUNCH BIOMASS FOR D-XYLOSE PRODUCTION
}

\author{
HERMAN SURYADI ${ }^{1,2 *}$, ARRY YANUAR ${ }^{2}$, HARMITA ${ }^{2}$, PUTRI WINNY RACHMADANI ${ }^{1}$ \\ ${ }^{1}$ Laboratory of Microbiology and Biotechnology, Faculty of Pharmacy, Universitas Indonesia. ${ }^{2}$ Laboratory of Pharmaceutical Chemistry, \\ Faculty of Pharmacy, Universitas Indonesia, Depok 16424, West Java, Indonesia. Email: hsuryadi@farmasi.ui.ac.id
}

Received: 13 January 2020, Revised and Accepted: 28 January 2020

\section{ABSTRACT}

Objective: The study aimed to identify the best conditions using oxalic acid for hydrolysis of hemicellulose in oil palm empty fruit bunch (OPEFB) biomass.

Methods: The analytical method of high-performance liquid chromatography (HPLC) was using a SUPELCOSIL LC-NH2 column, refractive index detection detector, and three compositions of the mobile phase. At first, the hydrolysis of hemicellulose in OPEFB powder was optimized by applying a response surface methodology. A three-variable, six-central composite design was used for the experiments. Temperature (between $95^{\circ} \mathrm{C}$ and $135^{\circ} \mathrm{C}$ ), reaction time (between 10 and $110 \mathrm{~min}$ ), and oxalic acid concentration (between $1 \%$ and $7 \%$ [w/v]) were evaluated by running 15 different experiments at constant biomass concentrations. Then, hydrolysis was optimized again at the constant temperature selected with three variables: OPEFB concentration, reaction time, and oxalic acid concentration. Hydrolysate samples were detoxified with carbon active, and furfural compound was analyzed by gas chromatography with flame ionization detector.

Results: The optimum condition of HPLC was using acetonitrile: water (9:1) at a flow rate of $1.0 \mathrm{ml} / \mathrm{min}$. The first hydrolysis results showed a high yield of D-xylose produced, which was $6.40 \mathrm{~g}$ D-xylose/100 g OPEFB biomass, with a xylose recovery of $93.8 \%$. However, this result was not yet optimum. Further hydrolysis at constant temperature experiment produced the highest xylose yield of $13.13 \%$, equivalent to 32 g/l D-xylose.

Conclusion: The yield of D-xylose from mild hydrolysis using oxalic acid was similar to that using dilute sulfuric acid as used in the previous study by Rahman et al.

Keywords: D-Xylose, Oxalic acid, Oil palm empty fruit bunch, Hydrolysate, Response surface methodology, Acid hydrolysis.

(c) 2020 The Authors. Published by Innovare Academic Sciences Pvt Ltd. This is an open access article under the CC BY license (http://creativecommons. org/licenses/by/4. 0/) DOI: http://dx.doi.org/10.22159/ijap.2020.v12s1.FF037

\section{INTRODUCTION}

Lignocellulosic materials are the largest renewable resources in the world at present, with about 10 billion tons produced annually [1]. In Indonesia, many kinds of lignocellulosic waste are produced, such as rice straw, sugarcane bagasse, and oil palm empty fruit bunches (OPEFBs). The largest amount of lignocellulosic waste is from OPEFB biomass, with about 40 million tons produced in 2010, but this waste has not been utilized optimally. Most of the waste is destroyed by combustion that can increase the levels of $\mathrm{CO}_{2}$ in the air and increase global warming. The relatively high content of hemicellulose $( \pm 30 \%)$ in agricultural wastes, especially OPEFB biomass, can be utilized as a source of xylose monomers that could potentially be used as raw material for industry [2-4].

One of the industrial products produced from D-xylose or lignocellulosic hydrolysate is xylitol, which is a sugar alcohol that is widely used as a sugar substitute for people with diabetes. Besides, xylitol is also efficacious as an anticariogenic agent to prevent cavities and widely used in food products, such as confectionery, and pharmaceutical products, such as for thin-coating films $[5,6]$.

The acid hydrolysis process can be performed using an acid solution, such as $\mathrm{HCl}$ and $\mathrm{H}_{2} \mathrm{SO}_{4}$. Dilute sulfuric acid (1\%-7\%) was used for the hydrolysis of OPEFB at a temperature of $90-140^{\circ} \mathrm{C}$ from 10 to $110 \mathrm{~min}$. The best results are obtained by hydrolysis with $2 \%$ sulfuric acid at a temperature of $119^{\circ} \mathrm{C}$ for $60 \mathrm{~min}$, with a xylose concentration of $31.1 \mathrm{~g} / \mathrm{l}$ [2]. Dilute sulfuric acid is often used for hydrolysis, but its use risks damage to metal equipment because of its corrosive nature [7].
Oxalate that can chelate $\mathrm{Mn}^{+++}, \mathrm{Fe}^{++}$, and other divalent cation is thought to have a role in the degradation of lignin and cellulose in whiterot fungi [8]. Oxalic acid is a strong organic acid with an ionization constant of $6.5 \times 10^{-2}$ and $6.1 \times 10^{-5}$, which is considerably stronger than acetic acid, and a little stronger than sulfuric acid as well [9]. For those reasons, hydrolysis of wood and other lignocellulosic materials have used oxalic acid [10-13].

The study aimed to identify the optimum conditions using oxalic acid for hydrolysis of OPEFB fiber to produce a hydrolysate containing high concentrations of xylose. We used response surface methodology (RSM) to design the hydrolysis experiments.

\section{METHODS}

Materials and preparation of OPEFBs

The following materials used in this study: Xylose standard, oxalic acid, phosphoric acid, furfural, and $\mathrm{Ca}(\mathrm{OH})_{2}$ from Merck; acetonitrile and methanol from JT Baker, and aquabidest from PT Widatra.

OPEFB biomass was obtained from palm oil mill CV Kresna Duta Agroindo, Province of Jambi, Sumatera, Indonesia. The OPEFBs that had been cleaned and dried in the sun were subsequently ground and sieved through a 60-mesh sieve. A biomass powder was obtained and then dried in an oven at a temperature of $105^{\circ} \mathrm{C}$ for $14 \mathrm{~h}$.

\section{Design of the hydrolysis experiments}

The experimental range and level of independent variables at constant weight are shown in Table 1. 
The design of the hydrolysis experiments was performed using RSM [14] and Design Expert version 8.071 software (Stat-Ease, Inc., Minneapolis, MN, USA). A rotatable central composite design was adopted with three variables: Temperature $\left({ }^{\circ} \mathrm{C}\right)$, reaction time (min), and oxalic acid concentration (\%). The experimental range and level of independent variables at constant temperature are shown in Table 2.

\section{Hydrolysis with oxalic acid}

Acid hydrolysis was performed in a $100-\mathrm{ml}$ vial. A 5.0-g amount of OPEFB dried biomass was weighed and placed into each vial carefully. A total of $30 \mathrm{ml}$ of oxalic acid solution (1, 2, 4, 6, and 7\% w/v) was added to each vial (ratio OPEFB biomass to acid=1:6). The hydrolysis temperature was varied between $95^{\circ} \mathrm{C}$ and $135^{\circ} \mathrm{C}$, and samples were collected at various time intervals between 20 and $100 \mathrm{~min}$, as designed. After cooling down at room temperature, the soluble hydrolysates were obtained by filtration to remove any solids. The filtrate was neutralized by the addition of solid $\mathrm{Ca}(\mathrm{OH})_{2}$ at $\mathrm{pH} 10$ and was then immediately neutralized to $\mathrm{pH} 6$ with $85 \%$ phosphoric acid. Next, the filtrates were centrifuged for $20 \mathrm{~min}$ at $2500 \mathrm{rpm}$ and then filtered through a $0.45-\mu \mathrm{m}$ filter for analysis.

The second hydrolysis was carried out at a constant temperature of $121^{\circ} \mathrm{C}$. Various amounts of OPEFB dried biomass (2.6-9.4 g) were weighed, and a total of $35 \mathrm{ml}$ of oxalic acid solution $(0.6 \%-7.6 \%)$ was added to each vial according to the experimental design. The temperature of the hydrolysis was varied, and the samples were processed as above.

\section{Detoxification of hydrolysate}

The hydrolysates obtained were treated with several different concentrations of activated carbon, specifically 1,2 , and $4 \% \mathrm{~b} / \mathrm{v}$, and then heated at $55^{\circ} \mathrm{C}$ for $60 \mathrm{~min}$. The length of the reaction was varied from 60 to $75 \mathrm{~min}$. The centrifugation supernatants were then filtered through a $0.20-\mu \mathrm{m}$ filter for analysis by gas chromatography (GC).

\section{Analytical methods}

Hydrolysates were analyzed by high-performance liquid chromatography (HPLC) (Shimadzu LC 10AD) using a SUPELCOSIL LC-NH2 column, $25 \mathrm{~cm} \mathrm{~L} \times 4.6 \mathrm{~mm}$ I.D. Three mobile phase variations, acetonitrile:water at 90:10, 85:15, and 75:25, were used at a flow rate of $1.0 \mathrm{ml} / \mathrm{min}$. The variation giving the highest resolution was selected for analysis of the samples. A 20- $\mu \mathrm{L}$ aliquot of each sample was injected onto the HPLC column and detected by a refractive index detector [15]. Analysis of furfural compounds was performed by GC (Shimadzu GC 17A) using a capillary column (CBP 10; $60 \mathrm{~m} \times 0.32 \mathrm{~mm}$ ), which contained VB-wax at a flow rate of $1.2 \mathrm{ml} / \mathrm{min}$, equipped with a flame ionization detector, integrator CBM-102. A temperaturegradient analysis was run starting at $70^{\circ} \mathrm{C}$ for $1 \mathrm{~min}$, increased to $180^{\circ} \mathrm{C}$ at $20^{\circ} \mathrm{C} / \mathrm{min}$, and held constant for $2 \mathrm{~min}$ [16]. The volume of injection was $1 \mu \mathrm{l}$.

\section{RESULTS AND DISCUSSION}

\section{Optimization of HPLC mobile phase and standard curve}

The HPLC analysis was performed using a column similar to that used by Rahman et al. (2007), with little mobile phase optimization. of the three mobile phase compositions tested, acetonitrile:water (9:1) gave the highest resolution and was selected for the analyses. Serial diluting standard solutions were made for a calibration curve of D-xylose. The dilutions were made from the mother liquor and seven standard solutions at 1000,6000,10,000,12,000,16,000, 18,000, and $20,000 \mathrm{ppm}$. The equation for the xylose standard curve was:

$$
y=-64178.32+110.091 x
$$

with a correlation coefficient $(\mathrm{r})=0.9995$

\section{Hydrolysis at constant OPEFB biomass concentration}

In this experiment, the central composite design specified $115^{\circ} \mathrm{C}$ for 60 min with $4 \%$ oxalic acid as the acid catalyst.
A 5.0-g amount of dried OPEFB biomass was weighed into a $100-\mathrm{ml}$ vial, and $30.0 \mathrm{ml}$ of oxalic acid solution was added. The variations of the hydrolysis experiments were carried out following the experimental design (Table 1) with 20 sets of experiments [17]. The central composite was 6 times, axial composite $3 \times 6$ times, and the factorial composite of $3 \times 8$ times, with a total of 48 runs. The results are shown in Table 3 .

The best hydrolysis results gave a yield of 6.4\%. This result was achieved under the central composite hydrolysis conditions of $115^{\circ} \mathrm{C}$ for $60 \mathrm{~min}$ using $4 \%$ oxalic acid. These results were similar to those obtained by Rahman et al. (2007); however, further examination showed that these conditions were not optimal and did not give the highest yield. The influence of each variable on the yield and concentration of D-xylose is shown in Fig. 1.

The effects of temperature and oxalic acid concentration showed a truncated curve (Fig. 1a and c), which meant that a temperature of $115^{\circ} \mathrm{C}$ and $4 \%$ oxalic acid were not the optimum conditions. The optimum conditions were a temperature between $115^{\circ} \mathrm{C}$ and $135^{\circ} \mathrm{C}$ and oxalate concentrations between $4 \%$ and $7 \%$. The influence of hydrolysis time showed a curve approaching the normal curve (Fig. 1b),

Table 1: Range and level of hydrolysis I at a constant weight

\begin{tabular}{llllllll}
\hline Independent variables & \multirow{2}{*}{ Symbol } & \multicolumn{7}{c}{ Range and level } \\
\cline { 3 - 7 } & & $\boldsymbol{- \alpha}$ & $\mathbf{- 1}$ & $\mathbf{0}$ & $\mathbf{1}$ & $\boldsymbol{+} \boldsymbol{\alpha}$ \\
\hline Temperature $\left({ }^{\circ} \mathrm{C}\right)$ & $\mathrm{X} 1=\mathrm{A}$ & 95 & 100 & 115 & 130 & 135 \\
Reaction time $(\mathrm{min})$ & $\mathrm{X} 2=\mathrm{B}$ & 10 & 30 & 60 & 90 & 110 \\
Acid conc. $(\%)$ & $\mathrm{X} 3=\mathrm{C}$ & 1 & 2 & 4 & 6 & 7 \\
\hline
\end{tabular}

Table 2: Range and level of hydrolysis II at a constant temperature

\begin{tabular}{lllllll}
\hline Independent variables & \multirow{2}{*}{ Symbol } & \multicolumn{7}{c}{ Range and level } \\
\cline { 3 - 7 } & & $\mathbf{- \alpha}$ & $\mathbf{- 1}$ & $\mathbf{0}$ & $\mathbf{1}$ & $+\boldsymbol{\alpha}$ \\
\hline Biomass conc. (g) & $\mathrm{X} 1=\mathrm{A}$ & 2.64 & 4 & 5 & 6 & 9.36 \\
Reaction time (min) & $\mathrm{X} 2=\mathrm{B}$ & 10 & 30 & 60 & 90 & 110 \\
Acid conc. (\%) & $\mathrm{X} 3=\mathrm{C}$ & 0.64 & 2 & 4 & 6 & 7.64 \\
\hline
\end{tabular}

Table 3: Results of hydrolysis at a constant biomass concentration

\begin{tabular}{|c|c|c|c|c|c|c|c|}
\hline \multirow[t]{2}{*}{ Run } & \multicolumn{4}{|c|}{ Variable* } & \multicolumn{2}{|c|}{$\begin{array}{l}\text { Xylose yield } \\
(\%)\end{array}$} & \multirow{2}{*}{$\begin{array}{l}\text { Avg } \\
\text { yield } \\
(\%) \\
\overline{\mathbf{y}}\end{array}$} \\
\hline & $A(x 1)$ & $B(x 2)$ & C (x3) & y1 & y2 & y3 & \\
\hline 1 & 130 & 90 & 6 & 6.745 & 6.760 & 5.165 & 6.223 \\
\hline 2 & 115 & 60 & 4 & 6.355 & - & - & 6.355 \\
\hline 3 & 100 & 30 & 2 & 0.650 & 0.810 & 0.745 & 0.735 \\
\hline 4 & 100 & 90 & 6 & 0.535 & 0.575 & 0.570 & 0.560 \\
\hline 5 & 115 & 60 & 4 & 6.520 & - & - & 6.520 \\
\hline 6 & 100 & 30 & 6 & 0.965 & 0.860 & 0.980 & 0.935 \\
\hline 7 & 115 & 60 & 4 & 6.495 & - & - & 6.495 \\
\hline 8 & 100 & 90 & 2 & 0.900 & 1.050 & 0.810 & 0.920 \\
\hline 9 & 95 & 60 & 4 & 0.505 & 0.480 & 0.550 & 0.512 \\
\hline 10 & 135 & 60 & 4 & 5.025 & 6.680 & 6.905 & 6.203 \\
\hline 11 & 115 & 60 & 7 & 6.615 & 5.145 & 6.650 & 6.137 \\
\hline 12 & 130 & 30 & 6 & 5.940 & 3.955 & 5.015 & 4.970 \\
\hline 13 & 130 & 90 & 2 & 6.020 & 6.180 & 6.385 & 6.195 \\
\hline 14 & 115 & 60 & 4 & 6.480 & - & - & 6.480 \\
\hline 15 & 115 & 60 & 4 & 6.385 & - & - & 6.385 \\
\hline 16 & 115 & 110 & 4 & 3.800 & 3.720 & 3.805 & 3.775 \\
\hline 17 & 115 & 60 & 4 & 6.180 & - & - & 6.180 \\
\hline 18 & 115 & 60 & 1 & 0.915 & 0.940 & 0.995 & 0.950 \\
\hline 19 & 130 & 30 & 2 & 3.520 & 4.045 & 4.420 & 3.995 \\
\hline 20 & 115 & 10 & 4 & 0.610 & 0.525 & 0.525 & 0.553 \\
\hline
\end{tabular}

${ }^{*}$ A: Temperature $\left({ }^{\circ} \mathrm{C}\right)$, B: Effect of hydrolysis time (min), C: Acid concentration (\%). y1, y2, and y3: Xylose yield (grams xylose/100 g EFB biomass) 
which meant that the optimal hydrolysis time at a temperature of $115^{\circ} \mathrm{C}$ and $4 \%$ oxalic acid was about $60 \mathrm{~min}$. This observation is similar to that obtained by Rahman et al. (2007) using dilute sulfuric acid.

\section{Statistical analysis}

Statistical analysis of the xylose yield obtained from the experiments showed a response ratio between the upper and lower yield values of $>10$ ( 12.78), which meant that the data needed to be transformed. The following square root transformation was used:

$$
y^{\prime}=(y+k)^{1 / 2} \text { and }(y+k)>0
$$

Use of the "Fit Summary" tools to find a suitable model suggested a quadratic model because of its higher R-squared value (0.8937) and relatively lower lack of fit value. The analysis of variance (ANOVA) results showed that a modified quadratic model had the highest $F$ value (13.76), which meant that the created model was significant $(\mathrm{p}<0.01)$ (Table 4).

From the quadratic models, an equation to calculate the xylose yield response was derived as follows:

\section{$\mathrm{Y}^{2}=2.48244+0.6958 \mathrm{~A}+0.1947 \mathrm{~B}+0.19113 \mathrm{C}+0.1099 \mathrm{AB}-0.3704$ $\mathrm{A}^{2}-0.3591 \mathrm{~B}^{2}-0.2521 \mathrm{C}^{2}$}

The good linearity of this equation is shown by the R-squared value of 0.889 , which meant that the variability in the responses was not high. This result was also supported by the value of "adequate precision" of 10.76, which meant that the signal response was very sensitive and above the limit of quantitation. In general, a minimum value of 4 is desirable for adequate precision. Descriptions of the models to find the optimum hydrolysis conditions are shown in Fig. 2.

After obtaining a significant model using RSM, model optimization was performed. Process optimization was performed by re-plotting the model over a narrower range. The best solution obtained was a condition at a level of "desirability" of $98 \%$ and gave a temperature of $130^{\circ} \mathrm{C}$ for 70 min using $4 \%$ oxalic acid concentration.

Based on the results of the optimization above, it is understandable that the optimum temperature recommended was quite high, too high of a temperature can lead to significant degradation of xylose to furfural compounds. A similar observation was also reported

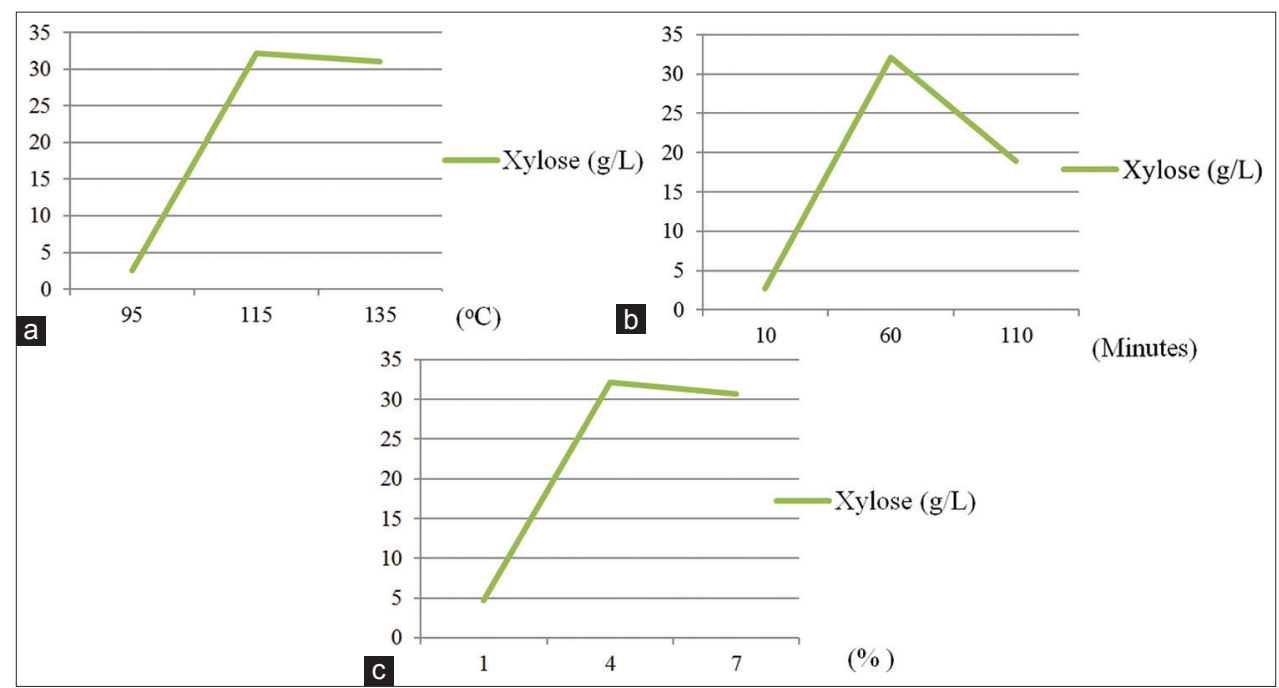

Fig. 1: Influence of each hydrolysis variable on xylose yield and concentration,(a) temperature, (b) hydrolysis time, (c) acid concentration

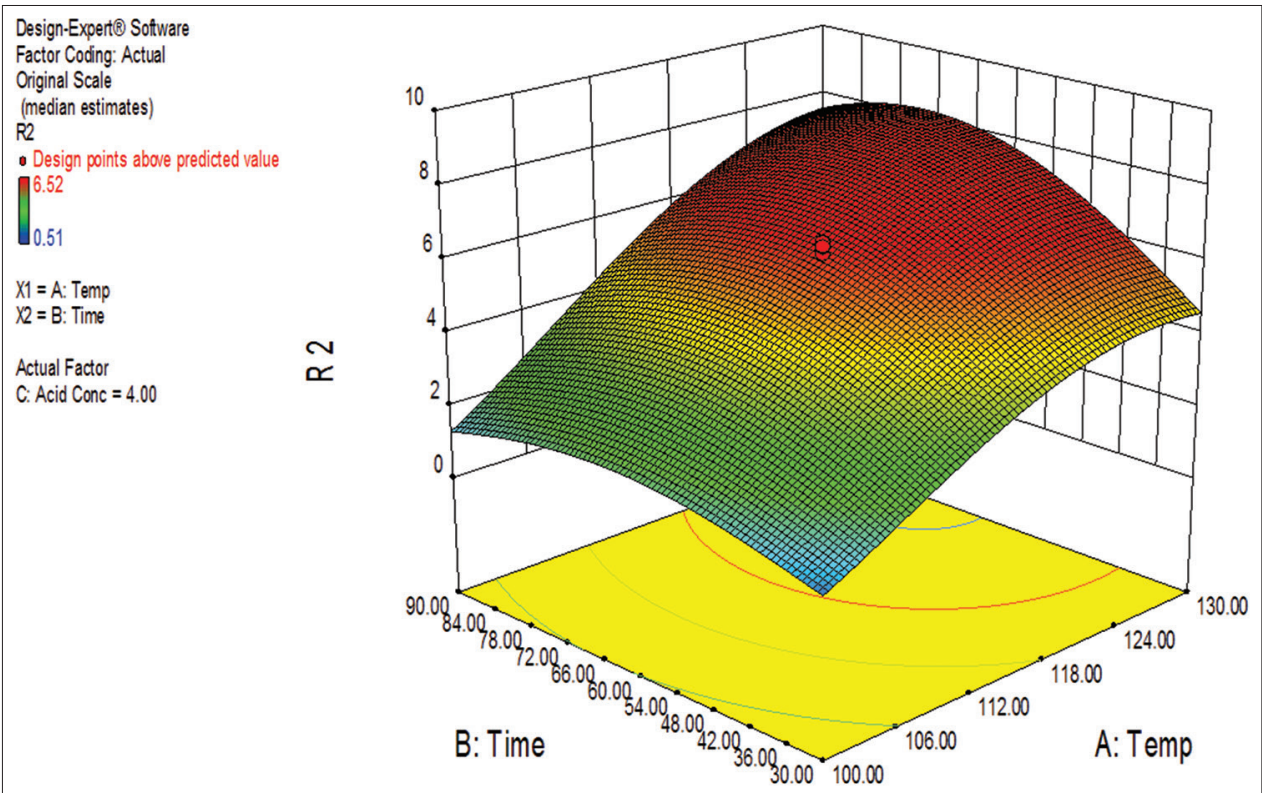

Fig. 2: Three-dimensional plot of xylose yield as a function of temperature versus time of reaction at a constant oxalic acid concentration (actual factor) 
by Rahman et al. (2007). Therefore, it was necessary to find the optimum conditions of hydrolysis at relatively lower temperatures that produced the highest yield of xylose. Based on the results of hydrolysis at a constant weight above, a temperature of $121^{\circ} \mathrm{C}$ was selected for subsequent hydrolysis. The optimization of hydrolysis was conducted, as shown in Table 2.

\section{Hydrolysis at a constant temperature}

The design and results of the experimental hydrolysis of OPEFB samples at constant temperature are summarized in Table 5. The hydrolysis process was designed using RSM with central composite conditions of an OPEFB weight of $6 \mathrm{~g}$ in $35 \mathrm{ml}$ of acid solution (1:6 w/v) using $4 \%$ oxalic acid for $60 \mathrm{~min}$. The crude hydrolysate was filtered and then neutralized by the addition of $\mathrm{Ca}(\mathrm{OH})_{2}$ slowly while stirring at $\mathrm{pH} 10$, followed by adjustment to $\mathrm{pH} 6.5$ with $85 \%$ phosphoric acid. This process led to the loss of glucose $(10 \%)$ and xylose $(4 \%)$. To reduce these losses, the time it took to change to high $\mathrm{pH}$ was shortened to minimize decomposition [18]. Centrifugation was performed to accelerate precipitation to obtain a clear supernatant before analyzing by HPLC.

The data analysis results were processed into two responses (R): Xylose concentration (g/l) as response $1(\mathrm{R} 1)$ and xylose yield (g/100 g biomass) as response 2 (R2). The data were statistically analyzed using RSM to obtain an appropriate model and yielded a quadratic model

Table 4: Analysis of variance (ANOVA) of the modified quadratic model

\begin{tabular}{llllll}
\hline Source & $\begin{array}{l}\text { Sum of } \\
\text { squares }\end{array}$ & df & $\begin{array}{l}\text { Mean } \\
\text { square }\end{array}$ & F value & $\begin{array}{l}\text { p-value } \\
\text { (Prob.>F) }\end{array}$ \\
\hline Model & 10.34126556 & 7 & 1.477324 & 13.76441 & $\begin{array}{l}<0.0001 \\
\text { (Sig.) }\end{array}$ \\
& & & & & $<0.0001$ \\
A-Temp & 5.595845685 & 1 & 5.595846 & 52.1371969 & $<130$ \\
B-Time & 0.513835809 & 1 & 0.513836 & 4.78747276 & 0.0492 \\
C-Acid & 0.456649548 & 1 & 0.45665 & 4.25466118 & 0.0615 \\
$\begin{array}{l}\text { Conc. } \\
\text { Lack of fit }\end{array}$ & 1.284771773 & 7 & 0.183539 & 288.66484 & $<0.0001$ \\
$\begin{array}{l}\text { Pure } \\
\text { error }\end{array}$ & 0.003179099 & 5 & 0.000636 & & \\
\hline
\end{tabular}

with modification (a reduced quadratic model). ANOVA for these models produced an $\mathrm{F}$ value $=2.78$, and a low $\mathrm{p}$-value $(\mathrm{p}<0.0575)$. This finding suggests that this model is quite significant. The precision of the obtained data response was 5.55, which indicated adequate precision and was higher than the minimal value (4.0). These models qualified for the navigation of space design.

Diagnostic models for each independent variable showed a difference in the optimum responses of studentized residuals. Factor A (biomass weight) had an optimum of $6 \mathrm{~g}$, Factor B (time) had an optimum of $85 \mathrm{~min}$, and Factor C (oxalic acid concentration) had an optimum of $4 \%$. The combination of these three variables produced optimum hydrolysis conditions that were slightly different from the optimum conditions for each variable.

On the contour plot, the actual Factor B (time) of 60 min gave an optimum xylose yield (R2) for OPEFB sample weights of about $6 \mathrm{~g}$ and an oxalic acid concentration of about $6 \%$. When the hydrolysis time was increased to $75 \mathrm{~min}$, the xylose yield increased from 6 to $8 \%$ at a concentration of $4 \%$ oxalic acid. This increase means that there was an interaction between the independent variables, and the xylose yield still increased with increasing concentrations of oxalic acid (Fig. 3).

The equations obtained from the RSM were obtained according from the following general equation:

\section{$\mathrm{Y}=34.00991-4.9116 \mathrm{~A}-0.4020 \mathrm{~B}-1.1379 \mathrm{C}+0.2519 \mathrm{AC}+0.2799 \mathrm{~A}^{2}+0.00$ $389 \mathrm{~B}^{2}$}

Where $\mathrm{Y}$ is the xylose yield response (R2), $\mathrm{A}=\mathrm{X} 1$ is the weight of OPEFB, and $\mathrm{B}=\mathrm{X} 2$ and $\mathrm{C}=\mathrm{X} 3$ are time and the acid concentration, respectively.

The actual analysis showed that the largest yield was obtained from the hydrolysis conditions of $6 \mathrm{~g}$ OPEFB weights, $85 \mathrm{~min}$, and $4 \%$ acid concentration. The results were $0.7898 \mathrm{~g}$ (R1) and a $13.13 \%$ xylose yield, with a xylose concentration of about $32 \mathrm{~g} / \mathrm{l}$. Although the optimum conditions of hydrolysis were also achieved during the first hydrolysis at higher temperatures $\left(130^{\circ} \mathrm{C}, 70 \mathrm{~min}\right)$, the second hydrolysis at the lower temperatures $\left(121^{\circ} \mathrm{C}, 85 \mathrm{~min}\right)$ was better because the milder conditions (lower temperature) gave less disintegration of cellulose and lower concentrations of furfural compounds (degradants). These conditions will enable wider use, such as for production of ethanol [19].

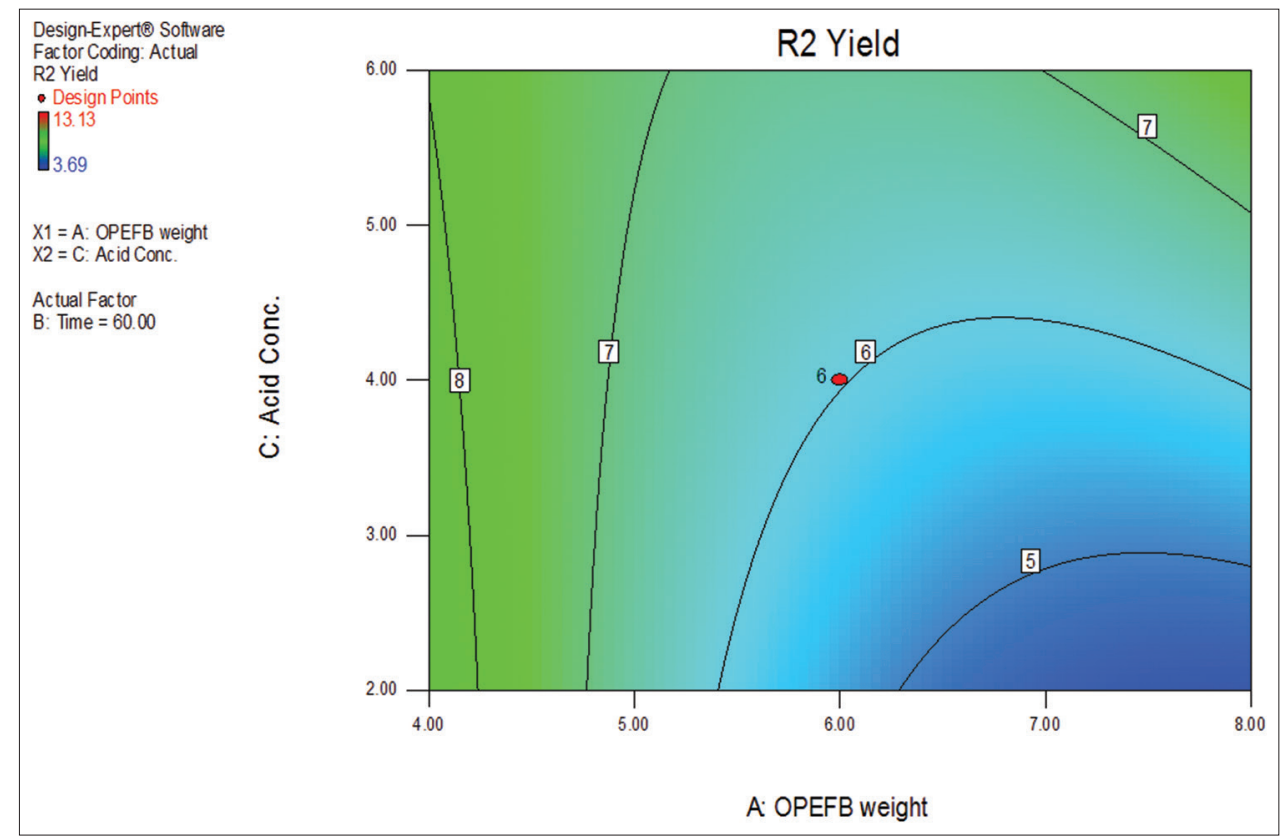

Fig. 3: Contour plot of oil palm empty fruit bunch biomass weight versus oxalic acid concentration to predict xylose yield (R2) when hydrolyzed at $121^{\circ} \mathrm{C}$ at a constant reaction time 
Optimization of hydrolysate detoxification by activated charcoal The OPEFB hydrolysate obtained was detoxified by activated charcoal [18]. Various concentrations of activated charcoal, 1, 2, and 4\% were examined and heated for $60 \mathrm{~min}$. A significant decrease in furfural compounds showed the effectivity of detoxification. Analysis of furfural compounds in each sample of hydrolysate was performed by GC, which showed that hydrolysate detoxified with $2 \%$ charcoal produced the greatest decrease in the furfural peak area relative to the furfural peak area before detoxification. Further optimization of the detoxification time showed that 75 min was better than 60 min and enabled $>90 \%$ of furfural compounds (data not shown). This highest absorption of furfural compounds can also be applied for the preparation of these basic compounds [20].

When the conditions and results of oxalic acid hydrolysis were compared with those of the diluted sulfuric acid hydrolysis carried out by by Rahman et al. [2], Kumar et al. [19], and Tan et al. [21], similar higher recovery of xylose was observed but under milder conditions. As a weak acid, oxalic acid needs a higher concentration of $4 \%$ to catalyze xylan degradation similar to that of $2 \%$ dilute sulfuric acid used in 60 min hydrolysis [2].

\section{CONCLUSION}

There were two main findings in this study: (1) The optimum mild hydrolysis conditions were a temperature of $121^{\circ} \mathrm{C}$ for an $85-\mathrm{min}$ reaction time, with a ratio of OPEFB sample to $4 \%$ oxalic acid of $1: 6$, and (2) detoxification of hydrolysate that still contains furfural can be performed by treatment of the hydrolysate with $2 \%$ activated charcoal at $60^{\circ} \mathrm{C}$ for $75 \mathrm{~min}$ to give decreased levels of furfural $>90 \%$.

\section{ACKNOWLEDGMENT}

The authors wish to thank the Directorate of Higher Education, Ministry of Research and Technology, Republic of Indonesia, for a research grant to Herman Suryadi.

\section{CONFLICTS OF INTEREST}

All authors have none to declare.

\section{REFERENCES}

1. Guo H, Chang J, Yin Q, Wang P, Lu M, Wang X, et al. Effect of the combined physical and chemical treatments with microbial fermentation on corn straw degradation. Bioresour Technol 2013;148:361-5.

2. Rahman SH, Choudhury JP, Ahmad AL, Kamaruddin AH. Optimization studies on acid hydrolysis of oil palm empty fruit bunch fiber for production of xylose. Bioresour Technol 2007;98:554-9.

3. Sudiyani Y, Sembiring KC, Hendarsyah H, dan Alawiyah S. Alkaline pretreatment and enzymatic saccharification of oil palm empty fruit bunch fiber for ethanol production. Menara Perkebunan 2010;78:70-4.

4. Hayashi K. Environmental Impact of the Palm Oil Industry in Indonesia. Proceeding of International Symposium on Eco Topia Science 2007, No. ISETS07; 2007.

5. Suryadi H, Katsuragi T, Yoshida N, Suzuki S, Tani Y. Polyol production by culture of methanol-utilizing yeast. J Biosci Bioeng 2000;89:236-40.

6. Zhang J, Geng A, Yao C, Lu Y, Li Q. Xylitol production from d-xylose and horticultural waste hemicellulosic hydrolysate by a new isolate of Candida athensensis sb18. Bioresour Technol 2012;105:134-41.

7. Mosier N, Wyman C, Dale B, Elander R, Lee YY, Holtzapple M, et al. Features of promising technologies for pretreatment of lignocellulosic biomass. Bioresour Technol 2005;96:673-86.

8. Hollister M. Review: Lignin conversion by manganese peroxidase (MnP). Enzyme Microbial Technol 2002;30:454-66.

9. Mosier NS, Sarikaya A, Ladisch CM, Ladisch MR. Characterization of dicarboxylic acids for cellulose hydrolysis. Biotechnol Prog 2001;17:474-80.

10. Torget RW, Kadam KL, Hsu TA, Philippidis GP, Wyman CE. Prehydrolysis Lignocellulose. Patent No. 5424217; 2002.

11. Lee JW, Rodrigues RC, Jeffries TW. Simultaneous saccharification and ethanol fermentation of oxalic acid pretreated corncob assessed with response surface methodology. Bioresour Technol 2009;100:6307-11.

12. Lee JW, Rodrigues RC, Kim HJ, Choi IG, Jeffries TW. The roles of xylan and lignin in oxalic acid pretreated corncob during separate enzymatic hydrolysis and ethanol fermentation. Bioresour Technol 2010;101:4379-85

13. Kim HY, Lee JW, Jeffries TW, Choi IG. Response surface optimization of oxalic acid pretreatment of yellow poplar (Liriodendron tulipifera) for production of glucose and xylose monosaccarides. Bioresour Technol 2011;102:1440-6.

14. Bradley N. The Response Surface Methodology. Indiana: Department of Mathematical Sciences, Indiana University of South Bend; 2007.

15. Joseph JK, Joseph LG. Practical HPLC Method Development. $3^{\text {rd }}$ ed. New York: John Wiley and Sons Inc.; 1997.

16. Rong C, Ding X, Zhu Y, Li Y, Wang L, Qu Y, et al. Production of furfural from xylose at atmospheric pressure by dilute sulfuric acid and inorganic salts. Carbohydr Res 2012;350:77-80

17. Khuri AI, Mukhopadhyay S. Response Surface Methodology. New York: John Wiley and Sons Inc.; 2010.

18. Roberto IC, Solange IM. Alternatives for Detoxification of DilutedAcid Lignocellulosic Hydrolyzates for Use in Fermentative Processes, a Review. Lorena, Brazil: Department of Biotechnology, Faculty of Chemical Engineering; 2003.

19. Kumar A, Singh LK, Ghosh S. Bioconversion of lignocellulosic fraction of water-hyacinth (Eichhornia crassipes) hemicellulose acid hydrolysate to ethanol by pichia stipitis. Bioresour Technol 2009;100:3293-7.

20. Delbecq F, Wang Y, Muralidhara A, El Ouardi K, Marlair G, Len C. Hydrolysis of hemicellulose and derivatives-a review of recent advances in the production of furfural. Front Chem 2018;6:146.

21. Tan HT, Dykes GA, Wu TY, Siow LF. Enhanced xylose recovery from oil palm empty fruit bunch by efficient acid hydrolysis. Appl Biochem Biotechnol 2013;170:1602-13. 